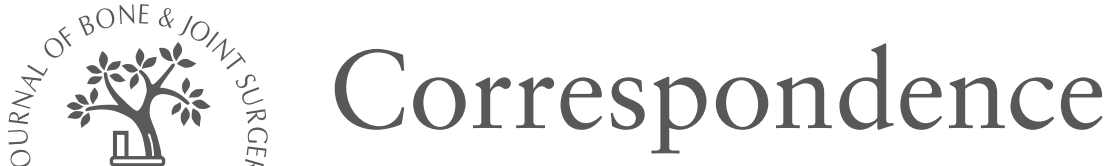

We welcome letters to the Editor concerning articles which have recently been published. Such letters will be subject to the usual stages of selection and editing; where appropriate the authors of the original article will be offered the opportunity to reply.

Letters should normally be under $\mathbf{3 0 0}$ words in length, doublespaced throughout, signed by all authors and fully referenced. The edited version will be returned for approval before publication.

(C)2005 British Editorial Society of Bone and Joint Surgery doi:10.1302/0301-620X87B5.16342\$2.00

$J$ Bone Joint Surg [Br] 2005;87-B:745-6.

\section{Pain in the well-fixed, aseptic titanium hip replacement: the role of corrosion}

Sir,

The value of Hallam, Haddad and Cobb's paper ${ }^{1}$ in the January 2004 issue is undoubtedly the clear description of this unusua syndrome involving the delayed onset of severe thigh pain in patients with cemented titanium femoral implants, which look radiologically sound despite femoral cortical hypertrophy. Their work confirms the earlier description of the condition. ${ }^{2}$ It is established that the combination of MMA cement and a titanium femoral prosthesis is now contra-indicated. However, the authors leave a number of questions unanswered.

I have been referred several such patients, the details of one of whom I have shared with the present authors, and whose radiographs are identical to those depicted in Figures $1 \mathrm{a}$ and $1 \mathrm{~b}$. If we are both referring to the same patient I consider the text which states that the patient "reached a stable level after three years" to be somewhat misleading. In fact after three years the pain resolved completely and, it is important to add, that the patient has remained pain free since, 14 years after the original surgery. The paper did concede that "the cortical hypertrophy has settled", and the latest radiographs demonstrating this would have made a useful addition to Figure 1. I have also encountered another patient whose symptoms have resolved spontaneously in a similar way.

The main question that has not been considered concerns the length of time during which it would be acceptable to observe the condition before recommending revision surgery. On the basis of surface corrosion, well-illustrated in their paper, and the crevice corrosion hypothesis (the nature of which is still under debate), the authors imply that the condition is a progressive one. They conclude that not only is revision surgery inevitable, but that the condition should be regarded as a failure of the prosthesis, which in this patient, so far, is not true.

The life span of a second-generation cemented and well-fixed femoral implant (even with some surface corrosion) against a revised uncemented one would undoubtedly provoke a debate among those who have studied implant longevity. ${ }^{3}$
M. A. EDGAR, MChir, FRCS

Emeritus Reader in Surgery, University College Hospitals, London, UK.

1. Hallam P, Haddad F, Cobb J. Pain in the wall-fixed, aseptic titanium hip replacement: the role of corrosion. J Bone Joint Surg [Br] 2004;86-B:27-30.

2. Willert H-G, Broback L-G, Buchhorn GH, et al. Crevice corrosion of cemented alloy stems in total hip replacements. Clin Orthop 1996;333:51-75.

3. Herberts $\mathbf{P}$, Malchau H. Long-term registration has improved the quality of hip replacements: a review of the Swedish THR Register comparing 160000 cases. Acta Orthop Scand 2000:71:111-21.

\section{Author's reply:}

Sir,

We thank Mr Edgar for his interest in our paper.

We can confirm that the patient whose radiographs are depicted in Figures $1 \mathrm{a}$ and $1 \mathrm{~b}$ was indeed a shared patient between the senior author of this paper and Mr Edgar. This patient was fascinating and was included because she was the one patient who reached a stable symptom-free level after three years. The patient in question was in severe pain for a number of years and many patients in her condition would have opted for revision surgery. Others have attempted a similar wait unsuccessfully and we have operated on several patients who have been in severe pain for between two and five years. It is interesting to note that $\mathrm{Mr}$ Edgar has encountered another patient whose symptoms resolved spontaneously.

We have never been able to explain satisfactorily the resolution of pain in this patient, although we did take that into account when thinking about mechanisms of pain in this condition. We believe that this phenomenon is caused by an electrical cell which relies on a thin layer of cement acting as a semi-permeable membrane allowing the partial oxidation states of titanium to continue their oxidation, generating a very low $\mathrm{pH}$. We hypothesise that with the passage of time, and the continued generation of protons, it may be that the deficient layer of cement at the tip of the implant was transformed from being a semi-permeable membrane to being more permeable, immediately abolishing the continued production of protons. In essence, the thin layer of cement was perforated by the acid, and so the cell was broken.

After reviewing a large number of further patients with this cemented implant over the last two years, there are a few whose symptoms settle to a thigh pain which can be uncomfortable and can trouble them at night, but that is not debilitating or progressive. They are often elderly and cope with their symptoms. It is definitely not usual for them to become symptom free. They typically continue to suffer significant intrusive pain but prefer to avoid further major surgery.

In relation to the question of how long one should observe before recommending revision surgery, we would reiterate that many of these patients are in severe pain and demand intervention. The minimum length of time between the onset of pain and surgery in the paper was 24 months. 
We have not stated that this condition is necessarily progressive. We, like Mr Edgar, have seen the described case where the symptoms resolved. In the majority, however, it remains a debilitating condition and it would be difficult to ask patients to wait three years or more and only then consider revision hip surgery. We believe that patients whose pain is worse and more intrusive after hip arthroplasty surgery than their original arthritic pain should be offered alternative treatment. The results of revision hip surgery are improving all the time. We believe the results of an uncemented revision femoral component that is well-fixed compare very favourably with the results of revision hip surgery ten to 20 years ago.

F. HADDAD, BSc, MCh(Orth), FRCS(Orth)

University College London Hospitals,

London, UK.

\section{Errata}

On page 1088 of the September 2004 issue, it is regretted that $\mathrm{Mr}$ Burge's name was incorrectly published as C. P. Burge, this should have been P. D. Burge.
M. Wick, D.K. Lester. Radiological changes in secondand third-generation Zweymüller stems

\section{J Bone Joint Surg [Br] 2004;86-B:1108-14.}

It is regretted that the legend for Figure 2 was incorrect. The correct Figure 2 is shown below:

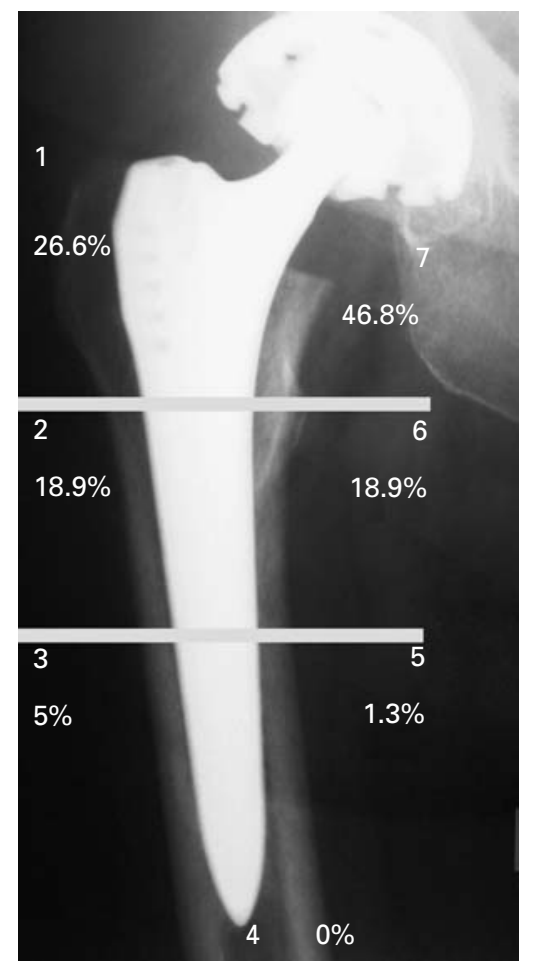

Fig. 2a

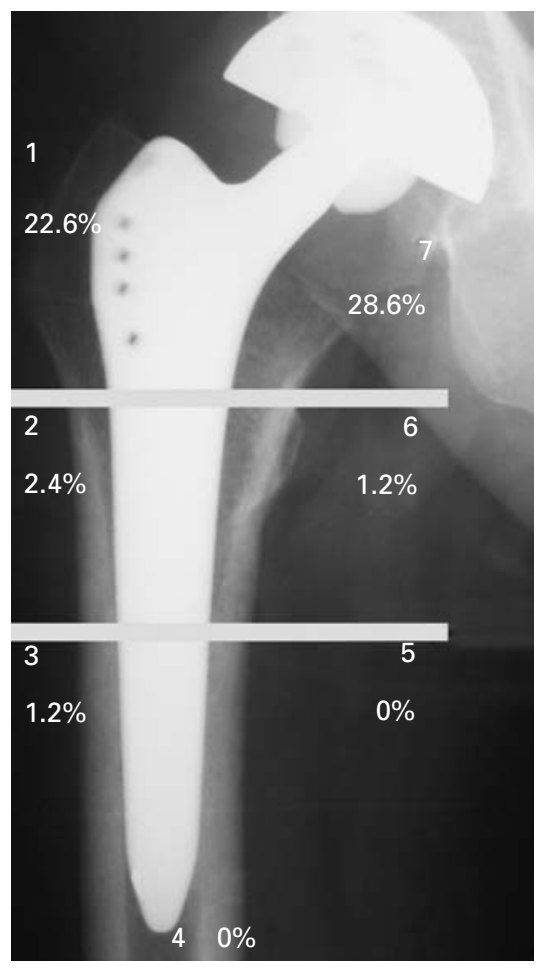

Fig. $2 b$
The incidence of stress shielding in a) the Endoplus stem and b) the Alloclassic stem. 